Research Article

\title{
Hypoplastic Interface Model considering Plane Strain Condition and Surface Roughness
}

\author{
Yong-Gwang Jong $\mathbb{D}^{1,2}$ Yang Liu $\mathbb{D}^{1},{ }^{1}$ Zixuan Chen $\mathbb{D},{ }^{1}$ and Pieride Mabe Fogang $\mathbb{D}^{1,3}$ \\ ${ }^{1}$ School of Civil \& Resource Engineering, University of Science and Technology Beijing, Beijing 100083, China \\ ${ }^{2}$ School of Material Engineering, Kim Chaek University of Technology, Pyongyang 999093, Democratic People's Republic of Korea \\ ${ }^{3}$ Department of Earth Sciences, University of Yaounde I, Yaounde, P. O. Box 812, Cameroon
}

Correspondence should be addressed to Yang Liu; yangliu@ustb.edu.cn

Received 10 May 2021; Accepted 18 August 2021; Published 31 August 2021

Academic Editor: Chaohui Wang

Copyright (C) 2021 Yong-Gwang Jong et al. This is an open access article distributed under the Creative Commons Attribution License, which permits unrestricted use, distribution, and reproduction in any medium, provided the original work is properly cited.

\begin{abstract}
The soil-structure interface problem is an important part of soil-structure interaction research. These problems are mostly threedimensional space problems, which is more complex to solve. In this paper, reduced stress and strain rate vectors are incorporated into the explicitly granular hypoplastic model by considering the plane strain state precisely. In addition, considering the important influence of roughness on the mechanical properties of contact surface, an improved hypoplastic model is established by incorporating the influence of roughness into the hypoplastic model, and the applicability of the new improved model is validated by comparing with the simulation results of the Mohr-Coulomb model, the explicitly granular hypoplastic models, and the experimental data. The results indicate that the improved model can be utilized to reflect the nonlinearity of the mechanical properties of the contact surface, which is in good agreement with the experimental data.
\end{abstract}

\section{Introduction}

The soil-structure contact surface is an important medium of transferring stress and strain between soil and structure. The unique mechanical properties of the contact surface have great influence on the strain and interaction between soil and structure. The study of mechanical properties of soilstructure interface has always been one of the important topics in civil engineering and geotechnics. In particular, interface modeling is an important part of simulating soilstructure contact behavior. Therefore, many researchers have proposed a large number of constitutive models.

In recent years, many interface models have been available, using elastic models, elastoplastic models [1-4], damage models $[5,6]$, and so on. Lashkari [1] proposed a plasticity model for the mechanical properties of sand-structure interfaces based on the critical state soil mechanics and the bounding surface plasticity theory. Boulon et al. [2] developed a strain-hardening elastoplastic model for the behavior of sand-structure contact surface under monotonic and cyclic loadings based on two plastic surfaces. Based on the disturbed state concept (DSC), Desai et al. [6] proposed a plastic model for liquefaction and stress-strain response of sand-concrete interfaces under dynamic conditions. Karalar and Cavusli [7] have used special material models (a WIPP-creep viscoplastic material model and a burger-creep viscoplastic material model) and studied the influences of the normal and shear stiffnesses on viscoplastic creep behavior of a concrete-faced rockfill (CFR) dam-foundation interface. Based on WIPPcreep viscoplastic material model and burger-creep viscoplastic material model, Karalar and Cavusli [8] have conducted the creep analyses of the concrete slab and rockfill materialsfoundation, respectively. Karalar and Cavusli [9] have modelled the Oroville dam using Flack3D and studied the effects of far fault earthquakes on the mechanical properties of dam body-foundation interface. However, these models are described by complex formulation and many parameters. Meanwhile, traditional elastoplastic theories such as flow rule, destruction rule, and hardening rule have to be taken into account, and many assumptions must be selected. 
Therefore, the hypoplastic models have attracted wide attention [10-14]. Fuentes et al. [10] developed a new constitutive model for sands by incorporating a loading surface with two hardening variables into a "Karlsruhe" hypoplastic model to reproduce memory effects and simulate plastic accumulation under cyclic loading. Based on a hypoplastic model with intergranular strains, Hleibieh et al. [11] presented a numerical model for a centrifuge experiment on tunnel embedded in sand under seismic loading. Li et al. [13] proposed a new macroelement developed within the framework of hypoplasticity to simulate the mechanical property of single vertical piles in sand. Based on the hypoplastic model by Gudehus [15] and Bauer [16], von Wolffersdorff [14] developed a new improved hypoplastic model with the asymptotic behavior. The models mentioned above are based on the nonlinear tensor function and written in few variables and a simple formulation. These models do not require elastoplastic theories such as yield surface, plastic potential, flow, and hardening laws and were developed without separating the deformation of the elastic and plastic parts. Therefore, compared to elastoplastic models, the hypoplastic models are more consistent with the actual situation and have obvious advantages in simulating the geotechnical mechanical properties.

In general, there are many factors affecting the mechanical properties of soil-structure interface, especially normal stress, relative density of soil, normal stiffness, structural surface roughness and hardness, and particle breakage, which have important effect on the mechanical property of the soil-structure contact surface [17]. Many researchers have conducted numerous experiments and simulations to prove the effect of roughness on the mechanical properties of contact surface [18-24]. Martinez and Frost [18] have performed laboratory experiments for friction sleeves sheared against sands to study the effect of surface roughness on the behavior of sand-structure contact surface. Haruyama [20] has conducted drained triaxial compression tests for the shear characteristics of uniform spheres of steel having different surface roughnesses to study the influence of surface roughness on the development of failure zone in the triaxial specimen. Wang et al. [23] developed the silicon piezoresistive sensor and used it to study the effect of roughness on the mechanical properties of the silty clay-concrete contact surface. Jensen et al. [24] have proposed an improved discrete element method (DEM) to simulate the mechanical property of granular mediastructure interface and prove the effects of roughness and particle shape on the shear response of contact surface. In order to provide a consistent interface behavior model, the hypoplastic model takes account of the frictional contact between soil and structure with different roughnesses. However, roughness has been taken into account in different ways [25-28]. Arnold and Herle [25] have proposed a hypoplastic model by incorporating the parameter $\kappa_{r}$ to describe the contact surface roughness and the parameter $\kappa_{r}$ was depended on the soil-soil friction angle and the interface friction angle. Stutz et al. [27] have considered the parameter $\kappa_{r}$ to depend on the contact surface roughness and established an enhanced hypoplastic interface model. In addition, hypoplastic models are mostly three-dimensional models that deal with space problems and require a lot of time and work. Therefore, some researchers have proposed two-dimensional hypoplastic interface models to reduce the CPU load [25, 27]. Arnold and Herle [25] have proposed the hypoplastic model for 2-D interface conditions and Stutz et al. [27] have developed an enhanced hypoplastic model by the incorporation of in-plane stresses into the model.

The research methods for the interface problems mentioned above are reviewed from the aspect of macromechanics. However, micromechanical analysis is also significant. Therefore, many researchers have conducted atomic scale simulation methods to study the interface problems. Based on the molecular dynamic modeling, Ghaffari et al. [29] carried out micronumerical simulations of mechanical properties of lubricant-sliding solids interface to study the effects of temperature and n-alkanes on the mechanical response of contact surface. Bai et al. [30] have used molecular dynamics model to simulate the friction and wear between diamond-like carbon (DLC) films and diamond tips with respect to micromechanical view and studied the effects of load, velocity, and surface roughness on the micromechanical response of contact surface.

Based on the existing granular hypoplastic model [14], in this paper, a new improved model has been developed by taking into account the relative surface roughness. In addition, the improved model was introduced with the reduced stress and strain tensors obtained by considering the plane strain condition precisely. Finally, the reliability of the improved interface model was validated by comparing with simulation results of the previous models and experimental data for different roughnesses.

\section{Hypoplastic Interface Model}

2.1. Stress and Strain Rate Tensor. Based on 2-D interface conditions, Arnold and Herle [25] proposed a 2-D hypoplastic interface model under the assumption of an isotropic stress state at the interface, while Stutz et al. [27] developed an enhanced model under the assumption of a transverse isotropic stress state at the interface.

In this paper, the new improved model was developed by considering the plane strain state precisely.

Figure 1 shows the soil-structure contact surface and the coordinate system. $u, v$, and $w$ are the displacement components in $x$-, $y$-, and $z$-directions, respectively. As shown in Figure 1, the size in one direction is much larger than two sizes in the other two directions, while the geometrical shape and size in the lengthwise direction do not change. The external force (normal stress $\sigma_{x}$ ) also acts parallel to the cross-section and does not change lengthwise. Therefore, the geometrical characteristics and external force of the soilstructure interface are the same as those of the plane strain problem. If we assume that any cross-section is the $x y$ plane, any line vertical to it is the $z$-axis, and the $z$-direction is infinitely long, then $\sigma_{x}, \sigma_{y}, \varepsilon_{x}, \varepsilon_{y}, u$, and $v$ do not change along the $z$-direction and are only functions of $x$ and $y$. As any cross-section can be considered as the plane of symmetry, then $w=0$ and the displacement vectors of all points are parallel to the $x y$ plane. 


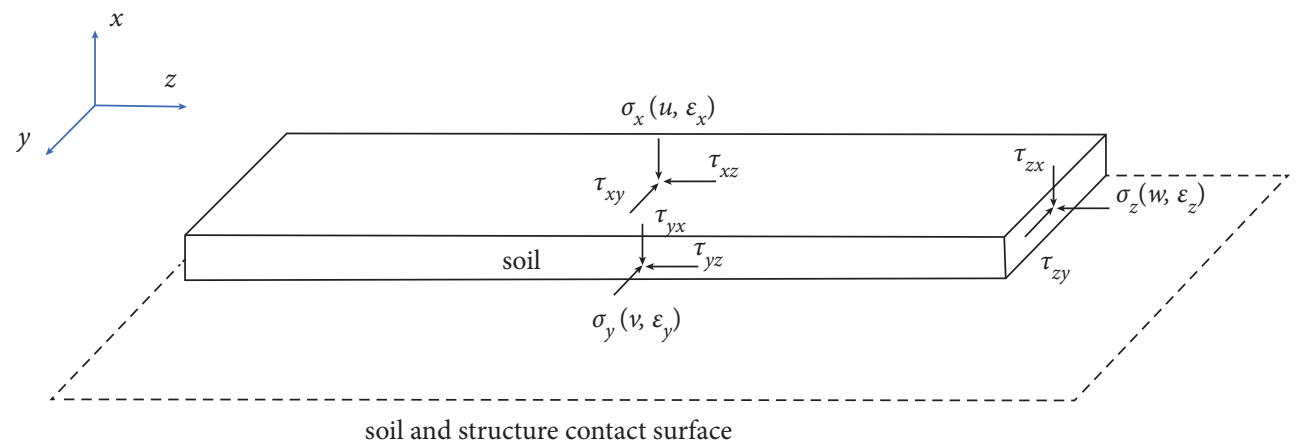

Figure 1: Contact surface and coordinate system.

In the plane strain state, the reduced stress tensor can be defined as

$$
\mathbf{T}=\left[\begin{array}{ccc}
\sigma_{x} & \tau_{x y} & 0 \\
\tau_{y x} & \sigma_{y} & 0 \\
0 & 0 & \sigma_{z}
\end{array}\right] .
$$

The degenerated vectorial $\mathbf{T}$ is written as

$$
\mathbf{T}=\left[\begin{array}{c}
\sigma_{x} \\
\sigma_{y} \\
\sigma_{z} \\
\tau_{x y}
\end{array}\right] .
$$

As shown in equation (2), the first input of the stress vector is the stress normal to the interface $\sigma_{x}$, the second and third inputs of the stress vector are the stresses normal to the interface in $y$ - and $z$-directions $\sigma_{y}$ and $\sigma_{z}$, respectively. The shear stress is $\tau_{x y}=\tau_{y x}$. As mentioned in equation (1), the shear stresses are $\tau_{x z}=\tau_{z x}=0$ and $\tau_{y z}=\tau_{z y}=0$; therefore, these are not incorporated into the vectorial notation.

The reduced strain rate tensor is written as

$$
\mathbf{D}=\left[\begin{array}{ccc}
\dot{\varepsilon}_{x} & \frac{1}{2} \dot{\gamma}_{x y} & 0 \\
\frac{1}{2} \dot{\gamma}_{y x} & \dot{\varepsilon}_{y} & 0 \\
0 & 0 & \dot{\varepsilon}_{z}
\end{array}\right] \text {. }
$$

The vectorial form $\mathbf{D}$ is defined:

$$
\mathbf{D}=\left[\begin{array}{c}
\dot{\varepsilon}_{x} \\
\dot{\varepsilon}_{y} \\
0 \\
\frac{1}{2} \dot{\gamma}_{x y}
\end{array}\right] \text {. }
$$

In the plane strain state, the strain in the $z$-direction is $\varepsilon_{z}=0$, so the third input of the strain rate vector is $\dot{\varepsilon}_{z}=0$. In order to match the stress vector to the strain vector, this is used in the strain rate vector. These reduced stress and strain rate tensors will be used to simulate the mechanical property of soil-structure interface.

2.2. Constitutive Formulation. The constitutive formulation used was defined by von Wolffersdorff [14]:

$$
\stackrel{\circ}{\mathbf{T}}=f_{b} f_{e} \frac{1}{\operatorname{tr}(\widehat{\mathbf{T}} \cdot \widehat{\mathbf{T}})}\left[F^{2} \mathbf{D}+a^{2} \widehat{\mathbf{T}} \operatorname{tr}(\widehat{\mathbf{T}} \cdot \mathbf{D})+f_{d} a F\left(\widehat{\mathbf{T}}+\widehat{\mathbf{T}}^{*}\right)\|\mathbf{D}\|\right],
$$

with

$$
a=\frac{\sqrt{3\left(3-\sin \varphi_{c}\right)}}{2 \sqrt{2 \sin \varphi_{c}}}
$$

where $\stackrel{\mathbf{T}}{ }$ and $\mathbf{D}$ are the objective stress rate and stretching tensor, respectively; $\widehat{\mathbf{T}}=\mathbf{T} / \operatorname{tr} \mathbf{T}$ is a deviator stress and the coefficient $a$ is defined by critical friction angle $\varphi_{c} ; \varphi_{c}$ is simply estimated from the angle of repose of loose material. According to the Matsuoka-Nakai [31] failure condition, the stress coefficient $F$ is written by

$$
F=\sqrt{\frac{1}{8} \tan ^{2} \phi+\frac{2-\tan ^{2} \phi}{2+\sqrt{2} \tan \phi \cos 3 \theta}}-\frac{1}{2 \sqrt{2}} \tan \phi,
$$

with the lode angle $\theta$,

$$
\cos 3 \theta=-6 \frac{\operatorname{tr}\left(\widehat{\mathbf{T}}^{*} \cdot \widehat{\mathbf{T}}^{*} \cdot \widehat{\mathbf{T}}^{*}\right)}{\left[\operatorname{tr}\left(\widehat{\mathbf{T}}^{*} \cdot \widehat{\mathbf{T}}^{*}\right)\right]^{3 / 2}}
$$

where $\widehat{\mathbf{T}}^{*}=\widehat{\mathbf{T}}-(1 / 3) \mathbf{1}$ is the deviator of $\widehat{\mathbf{T}} ; \mathbf{1}$ is the secondorder unity tensor and $\tan \phi=\sqrt{3}\left\|\widehat{\mathbf{T}}^{*}\right\| ; f_{b}$ is the barotropy factor which controls the effect of the mean stress and is given as

$$
f_{b}=\frac{h_{s}}{n}\left(\frac{e_{i 0}}{e_{c 0}}\right)^{\beta}\left(\frac{1+e_{i}}{e_{i}}\right)\left(\frac{-\operatorname{tr} \mathbf{T}}{h_{s}}\right)^{1-n}\left[3+a^{2}-a \sqrt{3}\left(\frac{e_{i 0}-e_{d 0}}{e_{c 0}-e_{d 0}}\right)^{\alpha}\right]^{-1} .
$$


The pycnotropy factors $f_{e}$ and $f_{d}$ control the influence of the relative density and are defined as

$$
\begin{aligned}
& f_{e}=\left(\frac{e_{c}}{e}\right)^{\beta}, \\
& f_{d}=\left(\frac{e-e_{d}}{e_{c}-e_{d}}\right)^{\alpha} .
\end{aligned}
$$

Pressure-dependent void ratios are defined by

$$
\frac{e_{i}}{e_{i 0}}=\frac{e_{c}}{e_{c 0}}=\frac{e_{d}}{e_{d 0}}=\exp \left[-\left(\frac{-t r \mathbf{T}}{h_{s}}\right)^{n}\right],
$$

where $e_{i}, e_{c}$, and $e_{d}$ are limiting void ratios; $e_{i 0}, e_{c 0}$, and $e_{d 0}$ are maximum void ratio, critical void ratio, and minimum void ratio at zero pressure, respectively. Under increasing mean pressure $p_{s}$, the limiting void ratios $e_{i}, e_{c}$, and $e_{d}$ decrease until the limiting values $e_{i 0}, e_{c 0}$, and $e_{d 0}$ are reached (Figure 2). In Figure 2, $p_{s}=-t r \mathbf{T} / 3$. The granular stiffness $h_{s}$ is the only parameter with the dimension of stress and is considered as the reference pressure. The exponent $n$ reflects the pressure-sensitivity of a grain skeleton. In addition, $\alpha$ controls the relative density to peak friction dependency and $\beta$ controls the relative density to the soil stiffness dependency.

2.3. The Contact Formulation considering Plane Strain Condition and the Surface Roughness. Arnold and Herle [25] assumed that the three normal stresses acting on the interface are equal, i.e., soil has isotropic properties, which do not match actual condition of the soil. Natural soils generally exhibit transverse isotropy $\left(\sigma_{y}=\sigma_{z}=\sigma_{p}\right)$ with an axis of rotational symmetry perpendicular to the deposition plane. As a result, equations (1) and (2) were redefined as follows:

$$
\begin{aligned}
& \mathbf{T}=\left[\begin{array}{ccc}
\sigma_{x} & \tau_{x y} & 0 \\
\tau_{y x} & \sigma_{p} & 0 \\
0 & 0 & \sigma_{p}
\end{array}\right], \\
& \mathbf{T}=\left[\begin{array}{c}
\sigma_{x} \\
\sigma_{p} \\
\sigma_{p} \\
\tau_{x y}
\end{array}\right] .
\end{aligned}
$$

The following formulation is defined by Dove and Jarrett [33] and Jin et al. [34]:

$$
\frac{\tan \delta_{p}}{\tan \varphi_{p}}=(1.373+2.402) \lg R,
$$

where $\tan \delta_{p}$ and $\tan \varphi_{p}$ are respectively the maximum friction coefficient of the sand-structure contact surface and sand under the same normal stress and $R$ is the surface roughness.

Based on Rowe's stress dilatancy theory, Bolton [35] proposed a relationship between the maximum friction angle $\delta_{P}$, maximum dilatancy angle $\psi$, and critical friction angle $\varphi_{c}$ :

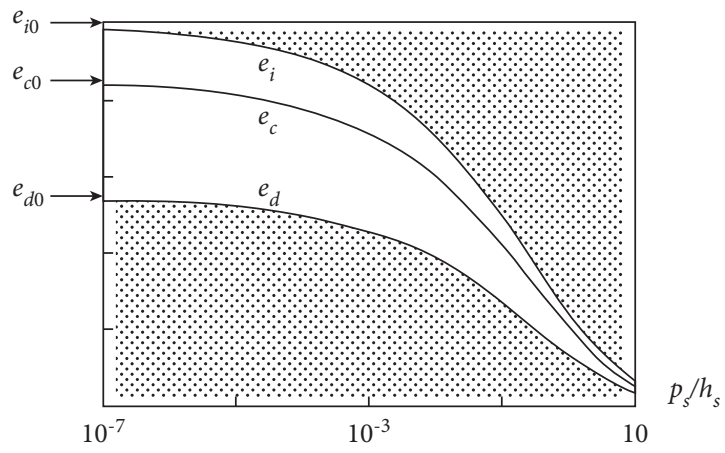

FIgURE 2: Relation between $e_{i}, e_{c}, e_{d}$, and $p_{s}$ in logarithmic scale [32].

$$
\delta_{P}=\varphi_{c}+0.8 \psi
$$

Combining equations (13) and (14), the critical friction angle of contact surface is written as

$$
\varphi_{c}=\arctan \left[(1.373+2.402 \lg R) \tan \varphi_{p}\right]-0.8 \psi \text {. }
$$

By substituting equation (15) in equation (6), it can be seen that the surface roughness $R$ has been included in the formulation of granular hypoplastic model.

\section{Simulation Method}

3.1. Simulation Model of Direct Shear. The direct shear simulation model was used to verify the new model by comparing with previous models. The size of the soil sample is $40 \times 10 \times 10 \mathrm{~cm}$ (Figure 3 ). The dimension of the structural part is $54 \times 18 \times 5 \mathrm{~cm}$ with the following characteristics: Young's modulus of $E=1 \mathrm{GPa}$ and Poisson's ratio of $v=0.25$. The structures of different roughnesses were used. The roughness $R$ is defined as the relative height between the highest peak and the lowest along a profile of structure surface. Figure 4 shows the profile of the applied roughness. As shown in Figure 4, the structural surface consisted of regular triangular asperities in the numerical simulation. Each regular triangle is an isosceles triangle and is exactly the same to each other; it contains two geometric parameters: the asperity height $(R)$ and the asperity width $(w)$. In this test, the width was set at $2 \mathrm{~mm}$ and height (roughness) was set according to the condition of experiment and simulation. The assembly was meshed by a linear interpolation of eight noded elements (C3D8). The entire loading process is divided into two stages; the first stage applies normal stress $\sigma_{n}$ on the top surface of the soil and, in the second stage, the soil is horizontally displaced by $u=7 \mathrm{~cm}$ in the positive direction. The friction characteristics of the contact surface are specified by the frictional subroutine (FRIC). The simulation was compared with the standard Mohr-Coulomb model and the explicitly granular hypoplastic models.

3.2. Simulation Scheme. During this research, we use the frictional subroutine (FRIC keyword in ABAQUS) to compile the new model into the FRIC subroutine; the aim is to simulate the mechanical property of the contact surface. 

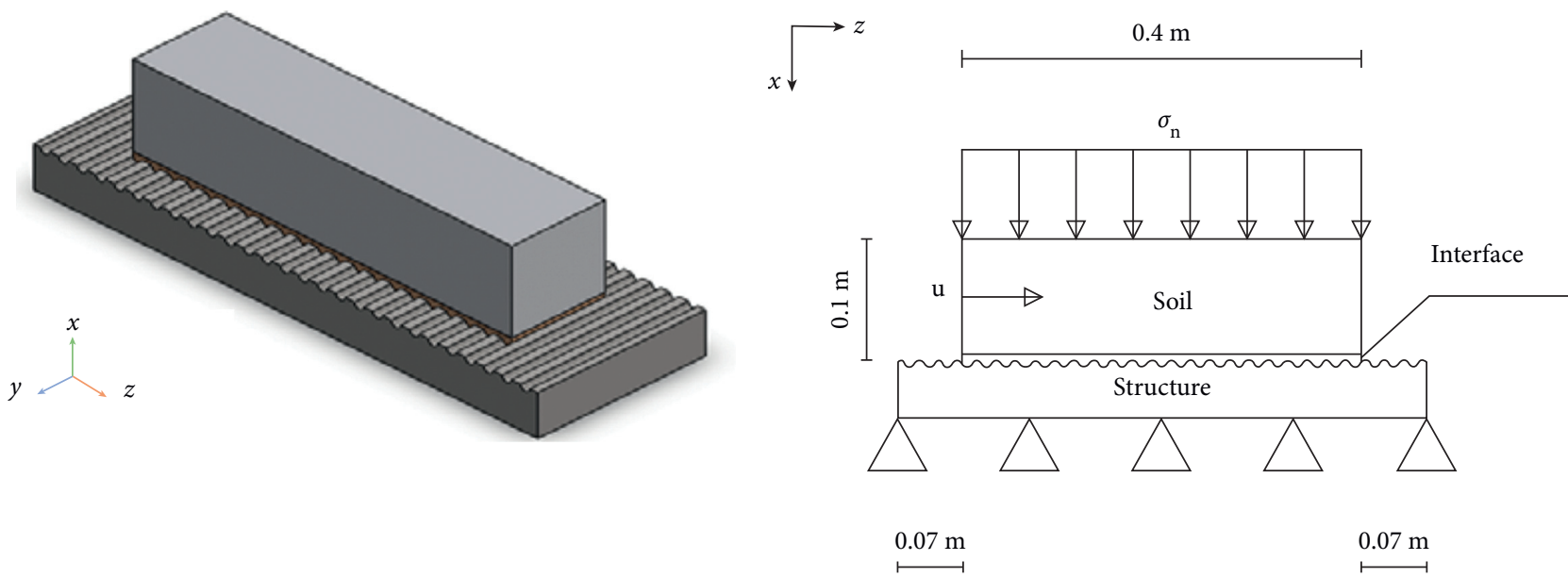

(a)

(b)

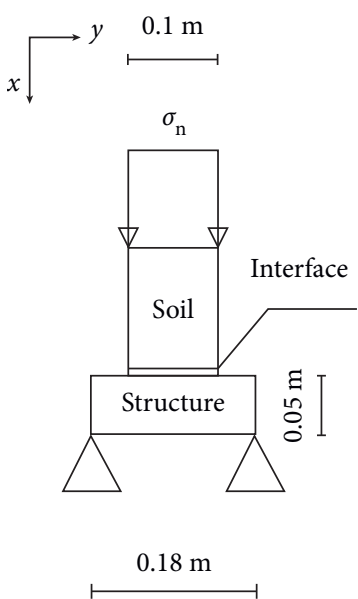

(c)

FIgURE 3: Schematic diagram of direct shear simulation model. (a) Isotropic view. (b) Front view. (c) Side view.

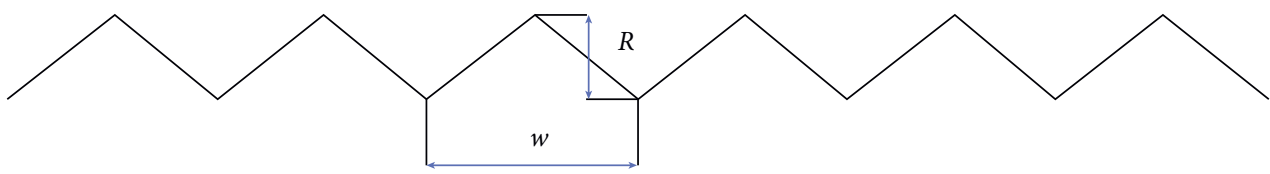

FIGURE 4: Profile of the applied roughness.

Figure 5 shows the operation flow of the FRIC subroutine. The parameters of the improved hypoplastic model $\varphi_{c}, h_{s}, n, e_{d 0}$, and so on, are inputted into the main program. After that, the contact state of soil-structure interface is estimated. If the interface is in contact, next stage (ABAQUS calculation kernel) is done, and if the interface is not in contact, it is returned to first stage. The stresses and displacements are calculated from the ABAQUS calculation kernel stage. In input FRIC stage, the reduced tensors (Section 2) are inputted to FRIC subroutine. In addition, the in-plane stress $\sigma_{p}$ and void ratio $e$ are inputted to this stage as additional state variables. In the next stage (Transformed to UMAT input), in order to access UMAT, input format of FRIC is formatted and transformed to UMAT subroutine. The stress $\sigma$ is calculated and updated by Jacobian matrix. After the UMAT call, if the relative error "err" is greater than the tolerance "TOL," it is gone to next stage (Newton-Raphson iteration), and if the relative error "err" is smaller than the tolerance "TOL," it is gone to Update FRIC stage. A new value of $\dot{\varepsilon}_{x}^{n+1}$ must be estimated by Newton-Raphson iteration until err $\leq$ TOL. In Update FRIC stage, the stress tensors $\mathrm{T}_{\mathrm{UMAT}}$ are transformed back to $\mathrm{T}_{\mathrm{FRIC}}$ for each increment.

\section{Results}

4.1. Comparison with Mohr-Coulomb Model. The Mohr-Coulomb model and the improved model are compared using the condition of direct shear simulation model (Section 3.1). The parameters for the Hostun sand used in the simulation are defined in Table 1 . The contact of the Mohr-Coulomb model is characterized only by the friction coefficient; it is decided to consider the roughness of the 


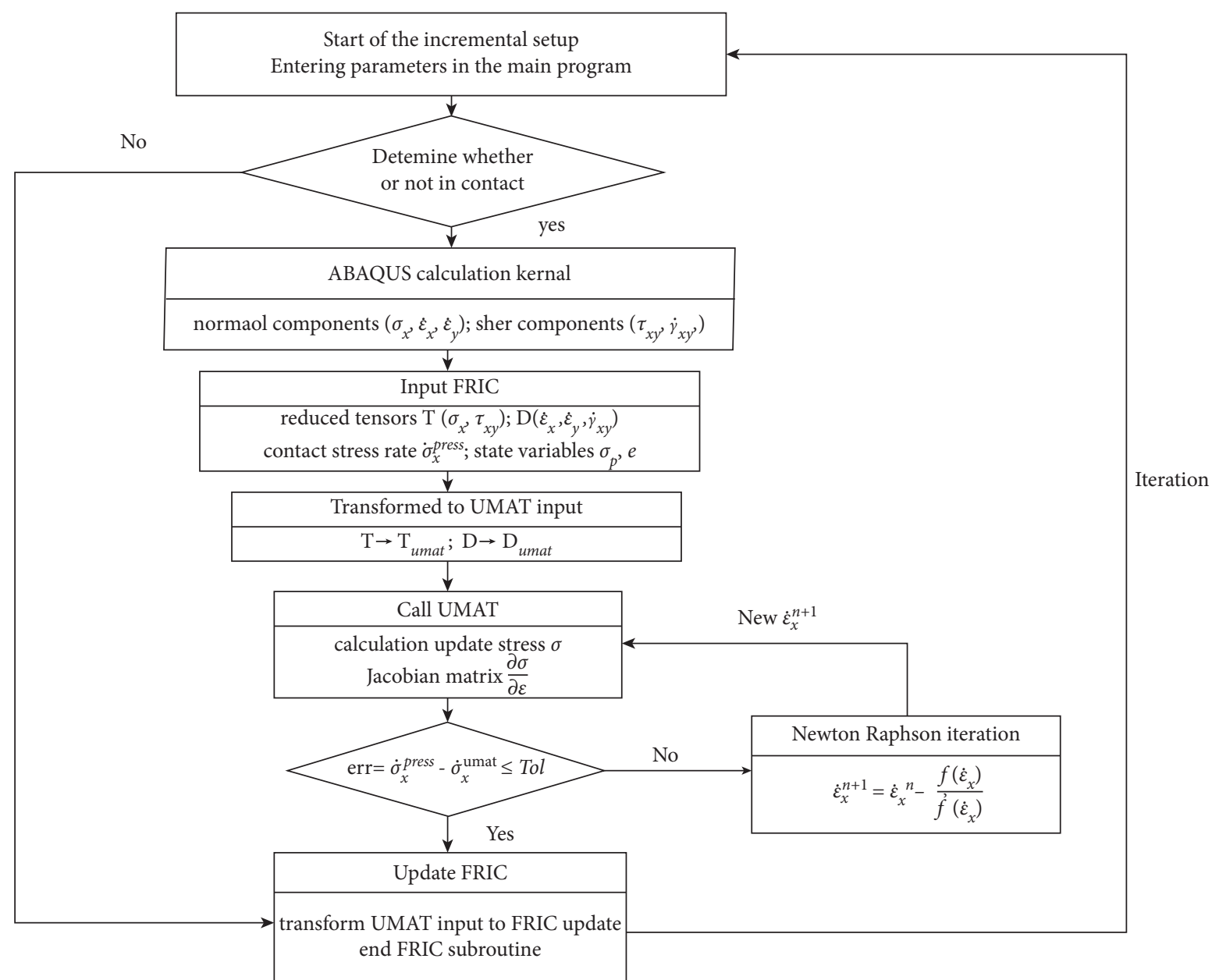

FIgURE 5: Schematic diagram for the FRIC subroutine with UMAT subroutine.

TABLe 1: Parameters for the evaluation of hypoplastic contact model (Hostun sand) [32].

\begin{tabular}{lc}
\hline Parameter & Value \\
\hline$\varphi_{c}\left(^{\circ}\right)$ & 31 \\
$h_{s}(\mathrm{MPa})$ & 1000 \\
$n$ & 0.29 \\
$e_{d 0}$ & 0.61 \\
$e_{c 0}$ & 0.96 \\
$e_{i 0}$ & 1.09 \\
$\alpha$ & 0.13 \\
$\beta$ & 2 \\
$\varphi_{p}\left({ }^{\circ}\right)$ & 39.6 \\
\hline
\end{tabular}

contact surface [36]. The two models were verified using normal stresses $\left(\sigma_{n}\right)$ of $100 \mathrm{kPa}$ and $200 \mathrm{kPa}$. The surface roughness was $46 \mu \mathrm{m}$. The relation between the shear stresses and shear displacements simulated by two models is shown in Figure 6. The default friction model is the Coulomb model of linear elasticity-ideal plasticity, so it cannot represent the hardening/softening properties of the contact surface, whereas the improved model is a typical nonlinear model; the results of the subroutine simulation are in good agreement with the actual condition of the contact surface and represent the effect of roughness and normal stress on the shear stress to the shear displacement. Consequently, it is proved that the new improved model is correct and feasible.

4.2. Comparison with the Explicitly Granular Hypoplastic Models. The model from Arnold and Herle [25], the model from Stutz et al. [27], and the improved model are based on the hypoplastic model from Wolffersdorff [14]. As described above (Section 2), the difference of three models lies in the interface conditions under the assumption of reduced stress and strain tensors. Therefore, the new improved model is compared to the model from Arnold and Herle [25] and the model from Stutz et al. [27].

In the following, the three models are simplified as

(i) Model proposed by Arnold and Herle [25]: $\mathrm{AH}$

(ii) Model proposed by Stutz et al. [27]: STZ

(iii) New improved model proposed in this paper: NEW

The three models use the same hypoplastic parameters, as shown in Table 1. The roughness of the contact surface for the three models was considered in the same way as that defined in Section 2.3. The applied normal stresses are $100 \mathrm{kPa}$ and $200 \mathrm{kPa}$; the applied roughnesses of the contact 


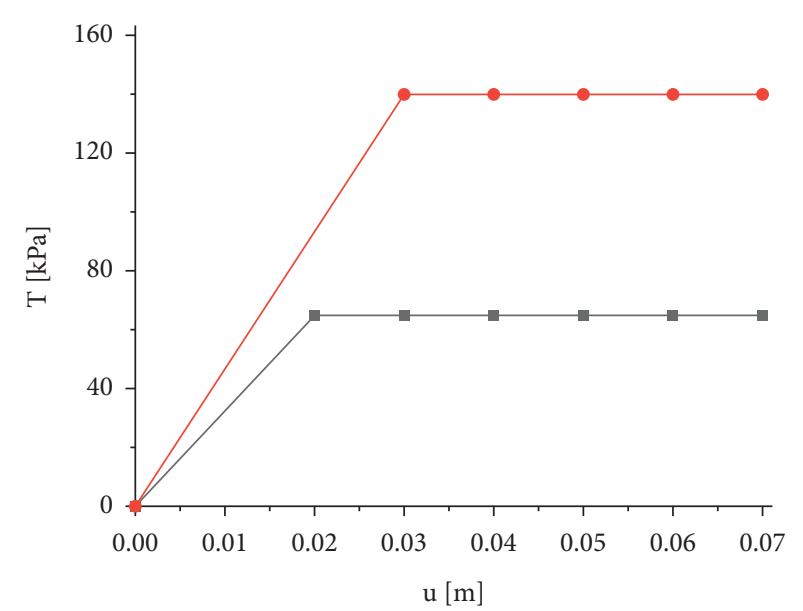

- $200 \mathrm{kPa}, \mathrm{Rmax}=46.0 \mu \mathrm{m}$

$\rightarrow 100 \mathrm{kPa}, \mathrm{Rmax}=46.0 \mu \mathrm{m}$

(a)

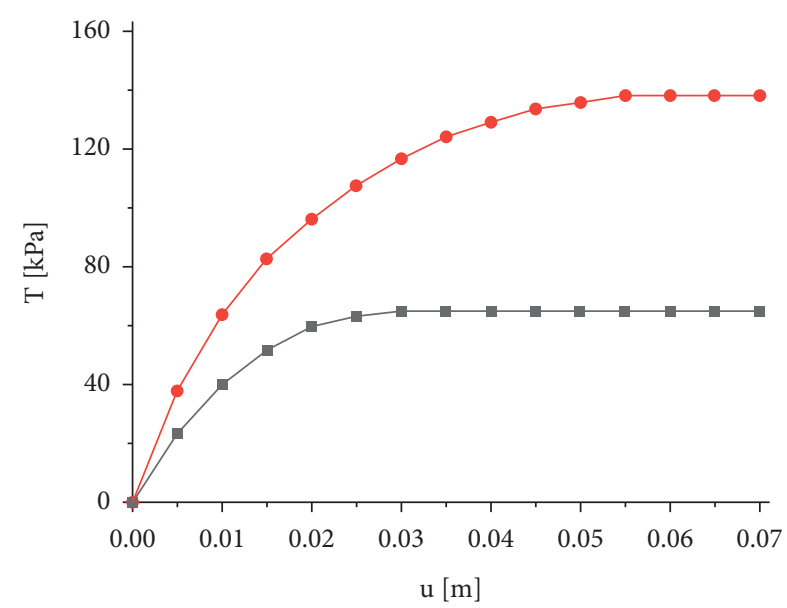

$\longrightarrow 200 \mathrm{kPa}, \mathrm{Rmax}=46.0 \mu \mathrm{m}$

$\rightarrow 100 \mathrm{kPa}, \mathrm{Rmax}=46.0 \mu \mathrm{m}$

(b)

Figure 6: Shear displacement $u$-shear stress $\tau$ for the comparison of Mohr-Coulomb (a) and the improved model (b).
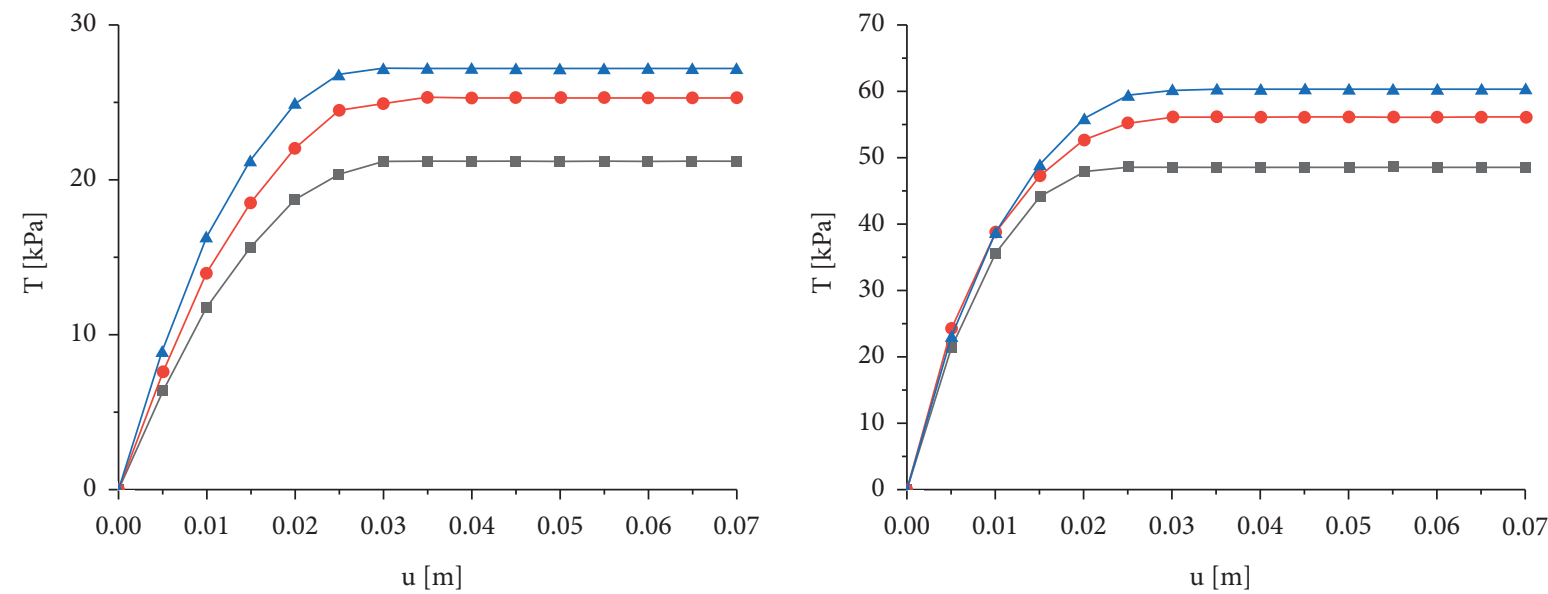

$$
\begin{aligned}
& \longrightarrow \mathrm{NEW}, 100 \mathrm{kPa}, \mathrm{Rmax}=2.4 \mu \mathrm{m} \\
& \rightarrow \mathrm{STZ}, 100 \mathrm{kPa}, \mathrm{Rmax}=2.4 \mu \mathrm{m} \\
& \rightarrow-\mathrm{AH}, 100 \mathrm{kPa}, \mathrm{Rmax}=2.4 \mu \mathrm{m}
\end{aligned}
$$

(a)

$$
\begin{aligned}
& \longleftarrow \mathrm{NEW}, 100 \mathrm{kPa}, \mathrm{Rmax}=20.5 \mu \mathrm{m} \\
& \longrightarrow \mathrm{STZ}, 100 \mathrm{kPa}, \mathrm{Rmax}=20.5 \mu \mathrm{m} \\
& \rightarrow \mathrm{AH}, 100 \mathrm{kPa}, \mathrm{Rmax}=20.5 \mu \mathrm{m}
\end{aligned}
$$

(b)

Figure 7: Continued. 

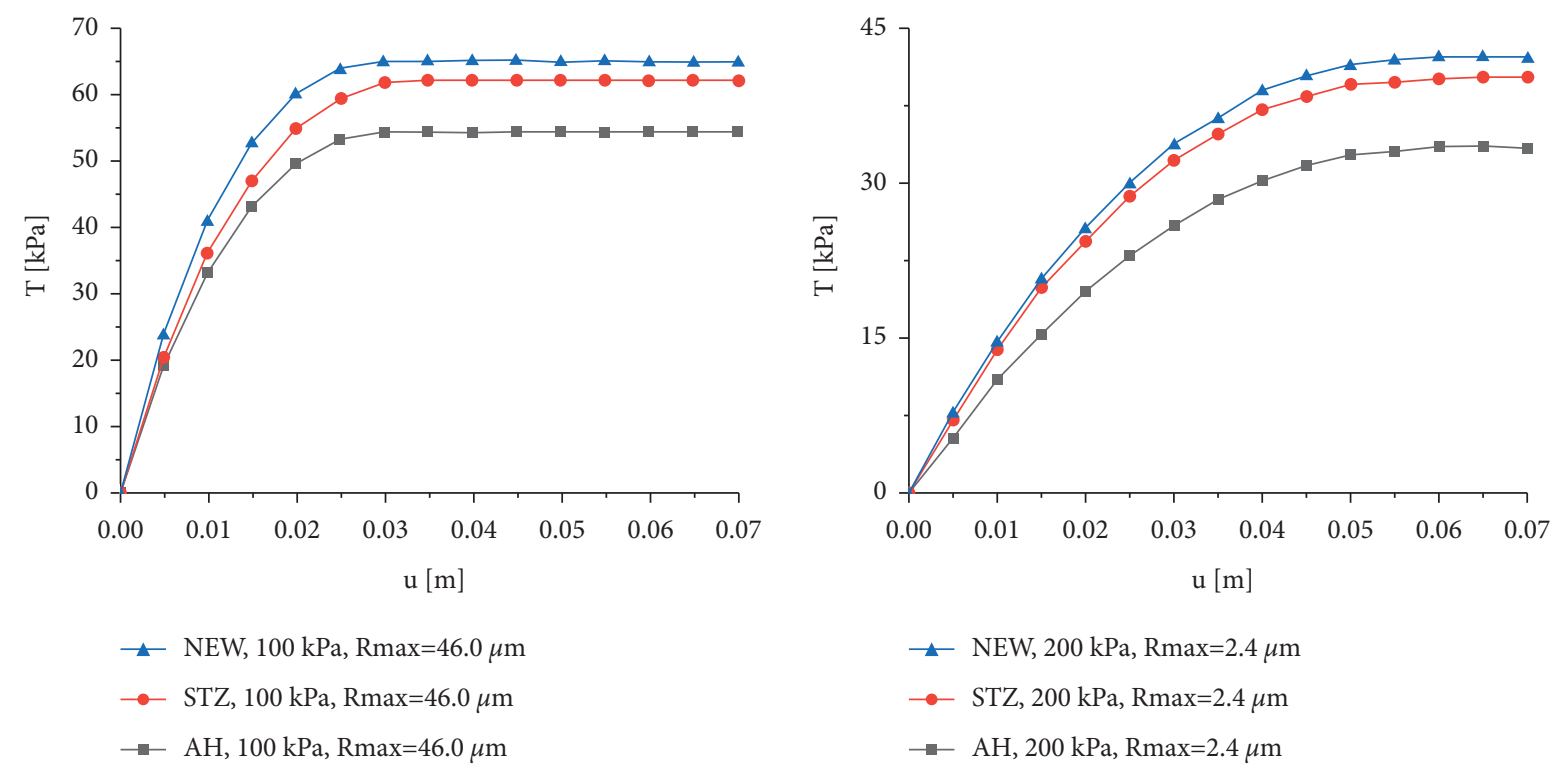

(c)

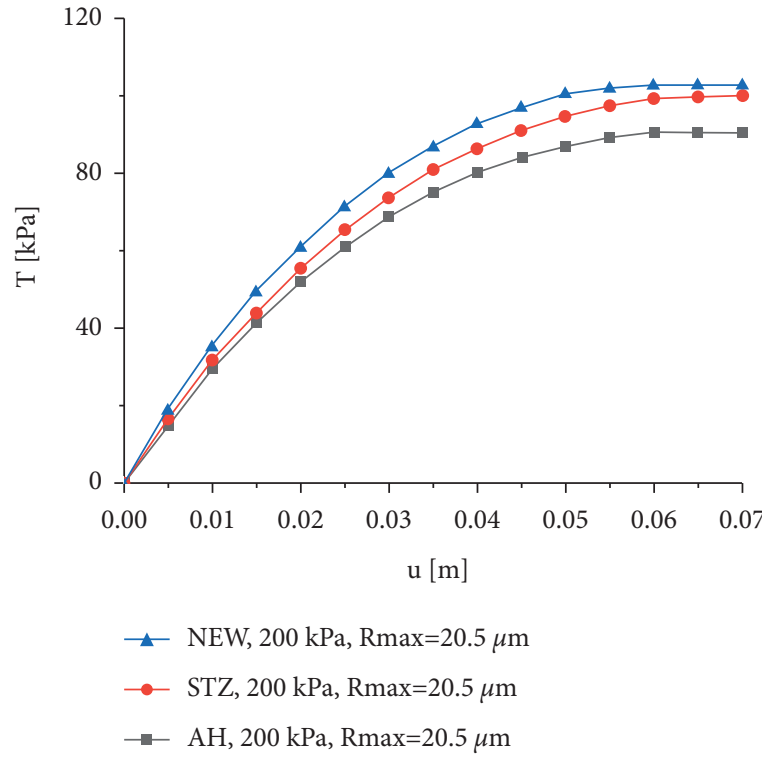

(e)

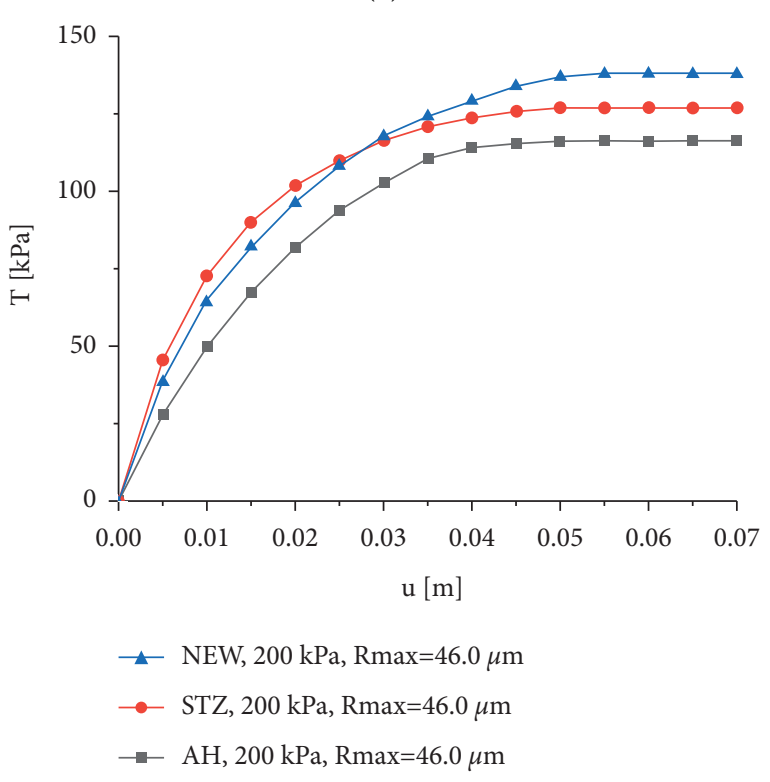

(f)

Figure 7: Shear displacement $u$-shear stress $\tau$ of the three models according to the surface roughness with $100 \mathrm{kPa}$ and $200 \mathrm{kPa}$ applied normal stresses.

surface are $2.4,20.5$, and $46.0 \mu \mathrm{m}$. Figure 7 shows the relation between the shear stresses and shear displacements of the three models according to the surface roughness with $100 \mathrm{kPa}$ and $200 \mathrm{kPa}$ applied normal stresses. The $\mathrm{AH}$ model gives the lowest shear stress at different roughnesses of the contact surface and different normal stress levels. The three models have the similar trend but the shear stresses obtained vary according to the roughness and the normal stress. In addition, in the cases of three models, the shear stresses increase as the surface roughnesses increase. This is the reason why the restraint effect of structural surface on soil in contact zone increases to raise the resistance of the sliding with the increase of surface roughness. This is also the reason that by increasing the surface roughness, the interface coefficient of friction increases so that the restriction on the soils by structures increases. As shown in Figures 7(a) - 7(f), in all cases, the difference between the improved model (NEW) and the STZ model is smaller compared to that between the new improved model and the $\mathrm{AH}$ model. This reason is the same as that described in Section 2: the improved model (NEW) and the STZ model have used the assumption of the transverse isotropy at the 
TABLE 2: Properties of the glass sand.

\begin{tabular}{lcccccc}
\hline Material & $D_{50}(\mathrm{~mm})$ & $C_{u}$ & Shape & $\rho_{s}\left(\mathrm{~g} / \mathrm{cm}^{3}\right)$ & $e_{\min }$ & $e_{\max }$ \\
\hline Glass sand & 0.95 & 1.41 & Angularity & 1.5 & 0.53 & 0.67 \\
\hline
\end{tabular}

TABle 3: Parameters for the evaluation of hypoplastic contact model (glass sand).

\begin{tabular}{lc}
\hline Parameter & Value \\
\hline$\varphi_{c}\left({ }^{\circ}\right)$ & 30 \\
$h_{s}(\mathrm{MPa})$ & 1700 \\
$n$ & 0.31 \\
$e_{d 0}$ & 0.53 \\
$e_{c 0}$ & 0.67 \\
$e_{i 0}$ & 0.80 \\
$\alpha$ & 0.14 \\
$\beta$ & 1 \\
$\varphi_{p}\left({ }^{\circ}\right)$ & 38 \\
\hline
\end{tabular}

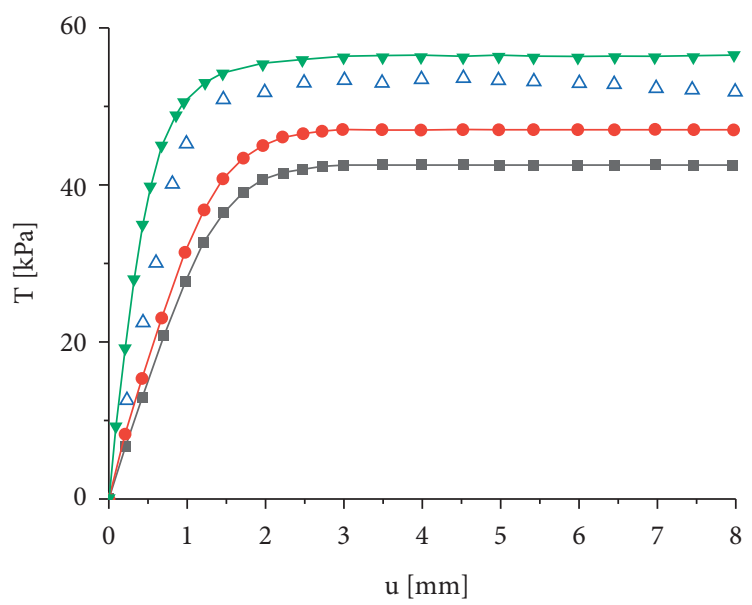

$\triangle$ experiment, $50 \mathrm{kPa}, \mathrm{Rmax}=0.1 \mathrm{~mm}$

$\rightarrow$ NEW, $50 \mathrm{kPa}, \mathrm{Rmax}=0.1 \mathrm{~mm}$

$\longrightarrow$ STZ, $50 \mathrm{kPa}, \mathrm{Rmax}=0.1 \mathrm{~mm}$

$\rightarrow \mathrm{AH}, 50 \mathrm{kPa}, \mathrm{Rmax}=0.1 \mathrm{~mm}$

(a)

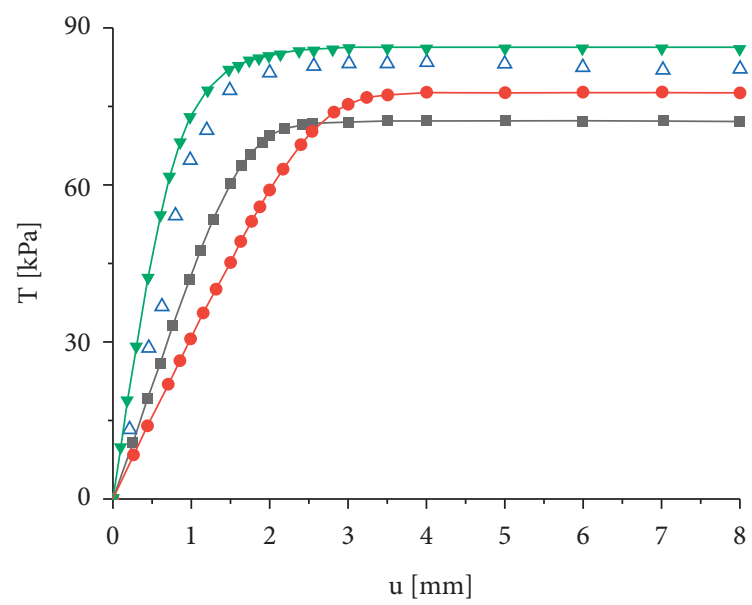

$\triangle$ experiment, $50 \mathrm{kPa}, \mathrm{Rmax}=1 \mathrm{~mm}$

$\sim$ NEW, $50 \mathrm{kPa}, \mathrm{Rmax}=1 \mathrm{~mm}$

- STZ, $50 \mathrm{kPa}, \mathrm{Rmax}=1 \mathrm{~mm}$

$\rightarrow \mathrm{AH}, 50 \mathrm{kPa}, \mathrm{Rmax}=1 \mathrm{~mm}$

(b)

Figure 8: Continued. 


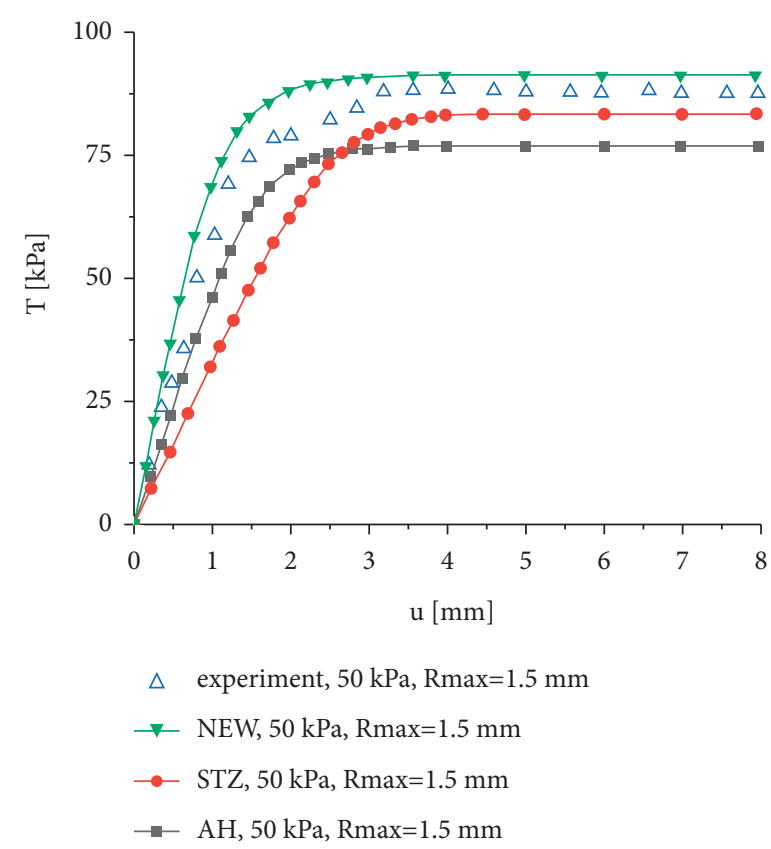

(c)

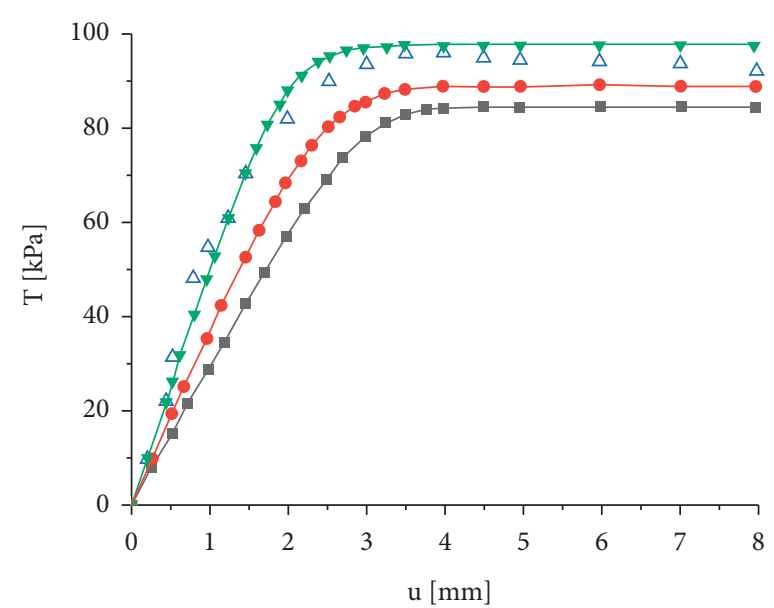

$\triangle$ experiment, $50 \mathrm{kPa}, \mathrm{Rmax}=2 \mathrm{~mm}$

$\checkmark$ NEW, $50 \mathrm{kPa}, \mathrm{Rmax}=2 \mathrm{~mm}$

$\longrightarrow \mathrm{STZ}, 50 \mathrm{kPa}, \mathrm{Rmax}=2 \mathrm{~mm}$

$\rightarrow \mathrm{AH}, 50 \mathrm{kPa}, \mathrm{Rmax}=2 \mathrm{~mm}$

(d)

Figure 8: Comparison of three models under the different surface roughnesses and an applied normal stress of $50 \mathrm{kPa}$ using our experimental data.

contact surface; however, the AH model has been proposed under the assumption of the isotropy at interface. As a result, the new improved model (NEW) and the STZ model show a small difference in their shear stress response.

4.3. Comparison with Experimental Results. The first verification is done by our experimental data. A direct shear experiment on the glass sand-concrete structure interface is conducted with an improved direct shear apparatus to analyze the effects of the roughness of the contact surface and the normal stress on the shearing strength of the interface. The properties of the glass sand are shown in Table 2. The used concrete plates have had relative surface roughnesses $R$ of $0.1,1,1.5$, and $2 \mathrm{~mm}$. The shear rate is $0.8 \mathrm{~mm} /$ min, and the cross-sectional area of the sample is $60 \times 60 \mathrm{~mm}$. The applied normal stresses are 50, 100, and $200 \mathrm{kPa}$.

The parameters of the glass sand were decided from previous study [32]. The parameters are given in Table 3. The new improved model (NEW) and the AH and the STZ models were compared with our experimental data. As described in Section 2.3, the roughness of the contact surface was considered in the same way. Figure 8 shows the relation between the shear stresses and shear displacements for the three models and our experimental data according to the surface roughness with $50 \mathrm{kPa}$ applied normal stress.

As shown in Figure 8, the simulation result of the new improved model (NEW) is the nearest to the experimental data in shear stress response than other two models. This reason is that the new improved model
(NEW) represents the mechanical property of the contact surface by considering the plane strain state precisely. As a result, the simulation results agree well with the experimental data.

Figure 9 shows the shear stresses-shear displacements of the three models and our experimental data according to the normal stress with $1 \mathrm{~mm}$ applied surface roughness. The three models show the similar response in shear behavior at different applied normal stress levels. However, the predictions obtained from the improved model (NEW) were better than those obtained from the AH and STZ models. This reason is that the improved model (NEW) has been proposed by considering the plane strain condition precisely and more exactly simulates the mechanical property of the contact surface than other two models.

The last verification is done by using experimental data by Shahrour and Rezaie [37]. They used modified direct shear box to study the effect of surface roughness $\left(k_{r}=1.0 /\right.$ $\left.R_{\max }=46.0 \mu \mathrm{m}\right)$ on the relation between shear stress and shear strain under the constant normal stress $\left(\sigma_{n}=100 \mathrm{kPa}\right)$. The sample was Hostun sand $\left(e_{0}=0.95\right)$ and the parameters are given in Table 1 . The new improved model (NEW) and the AH and the STZ models were used to reproduce the experimental data; the results are illustrated in Figure 10. As shown in Figure 10, three models simulate the hardening properties of the contact surface for loose sand. In particular, the simulation result of the new improved model (NEW) agrees better with the experimental data than those of other two models. This reason is that the improved interface model (NEW) considers the plane strain condition at the contact surface to represent the real state more accurately than the 


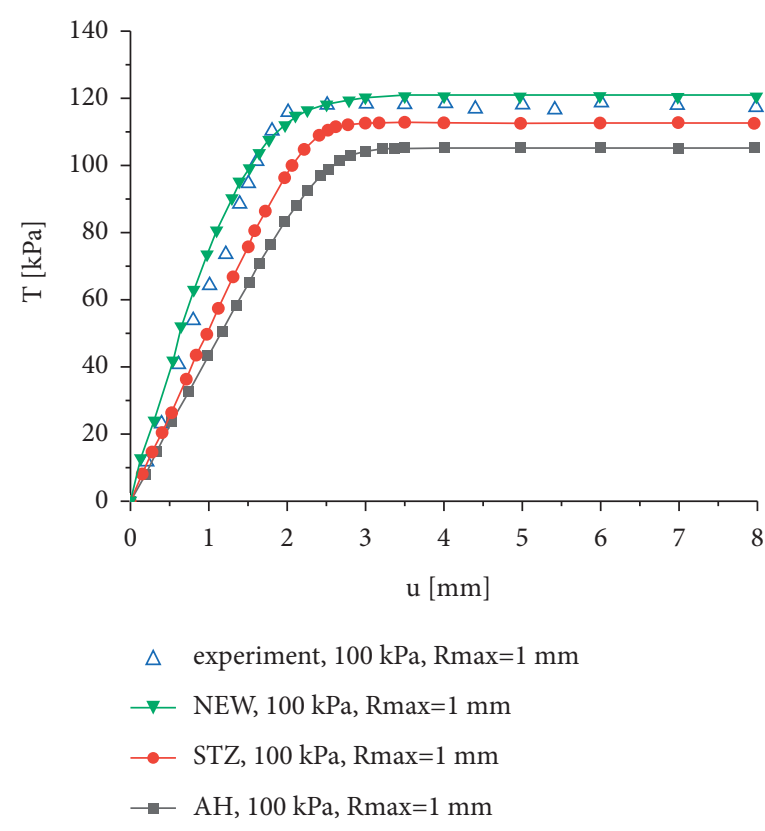

(a)

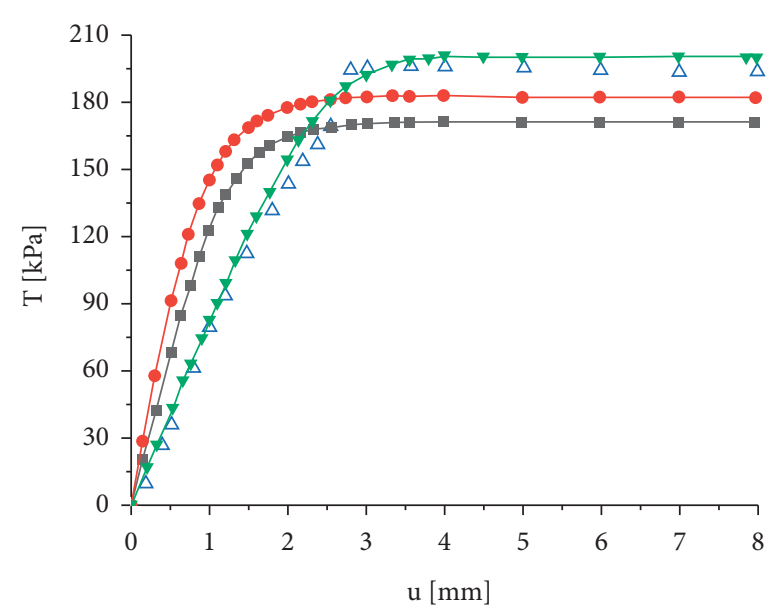

$\triangle$ experiment, $200 \mathrm{kPa}, \mathrm{Rmax}=1 \mathrm{~mm}$

$\rightarrow$ NEW, $200 \mathrm{kPa}, \mathrm{Rmax}=1 \mathrm{~mm}$

$\longrightarrow$ STZ, $200 \mathrm{kPa}, \mathrm{Rmax}=1 \mathrm{~mm}$

$\rightarrow \mathrm{AH}, 200 \mathrm{kPa}, \mathrm{Rmax}=1 \mathrm{~mm}$

(b)

FIGURE 9: Comparison of three models under the different normal stresses and an applied surface roughness of $1 \mathrm{~mm}$ using our experimental data.

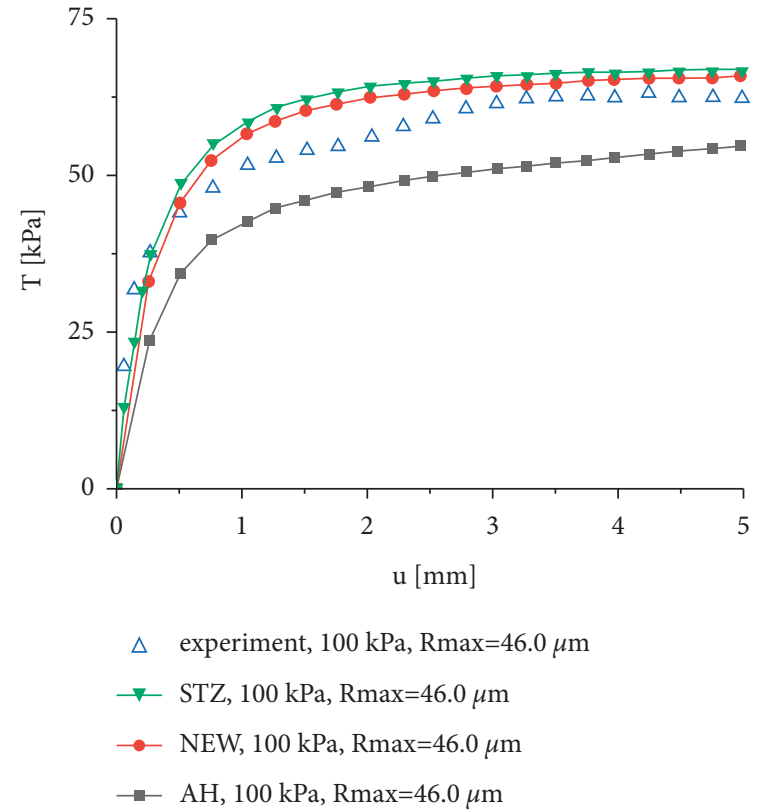

FIGURE 10: Comparison of three models with the experimental data by Shahrour and Rezaie [37].

previous models. Therefore, it is found that the new model has high reliability.

\section{Summaries and Conclusions}

The new improved model is incorporated by new reduced stress and strain rate tensors. The stress and strain rate tensors have been reduced by considering the plane strain condition accurately. Considering the relation between the relative roughness $R$ and critical friction angle $\varphi_{c}$, the roughness of the contact surface has been also introduced into the new improved model.

The new model was compared to the Mohr-Coulomb model. The result shows a better prediction with the new model. The new improved model is a typical nonlinear model, so it represents the hardening/softening properties of the contact surface. The new model was compared to the model developed by Arnold and Herle [25] (AH) and the model proposed by Stutz et al. [27] (STZ). The difference between the new model and the STZ model is smaller compared to that between the new model and the AH model.

The simulation results of the new improved model are close to the experimental data. These were demonstrated by the comparison of our test and the experimental data from Shahrour and Rezaie [37].

The new improved model represents the effects of roughness and normal stress on the shear stress to the shear displacement. The new model has advantage to reduce calculation time. The limitation of the improved model is that interface problem under monotonic loading can only be modelled. In the future, the proposed model may be widely used to solve boundary value problems such as interface problem under cyclic loading.

\section{Data Availability}

The data used to support the findings of this study are available from the corresponding author upon request.

\section{Conflicts of Interest}

The authors declare that they have no conflicts of interest. 


\section{Acknowledgments}

The authors appreciate the financial support of science and technology project of PowerChina Road Bridge Group Co., Ltd., and the National Natural Science Foundation of China (grant no. 51178044).

\section{References}

[1] A. Lashkari, "A plasticity model for sand-structure interfaces," Journal of Central South University, vol. 19, no. 4, pp. 10981108, 2012.

[2] M. Boulon, V. Ghionna, and G. Mortara, “A strain-hardening elastoplastic model for sand-structure interface under monotonic and cyclic loading," Mathematical and Computer Modelling, vol. 37, no. 5, pp. 623-630, 2003.

[3] K. Fakharian and E. Evgin, "Elasto-plastic modelling of stresspath-dependent behaviour of interfaces," International Journal for Numerical and Analytical Methods in Geomechanics, vol. 24, no. 2, pp. 183-199, 2000.

[4] A. Zhou and T. Lu, "Elasto-plastic constitutive model of soilstructure interface in consideration of strain softening and dilation," Acta Mechanica Solida Sinica, vol. 22, no. 2, pp. 171-179, 2009.

[5] S. K. Pradhan, C. S. Desai, and S. D. Chandra, "DSC model for soil and interface including liquefaction and prediction of centrifuge test," Journal of Geotechnical and Geoenvironmental Engineering, vol. 132, no. 2, pp. 214-222, 2006.

[6] C. S. Desai, S. K. Pradhan, and D. Cohen, "Cyclic testing and constitutive modeling of saturated sand-concrete interfaces using the disturbed state concept," International Journal of Geomechanics, vol. 5, no. 4, pp. 286-294, 2005.

[7] M. Karalar and M. Çavuşli, "Effect of normal and shear interaction stiffnesses on three-dimensional viscoplastic creep behaviour of a CFR dam," Advances in Civil Engineering, vol. 2018, Article ID 2491652, 17 pages, 2018.

[8] M. Karalar and M. Cavusli, "Examination of 3D long-term viscoplastic behaviour of a CFR dam using special material models," Geomechanics and Engineering, vol. 17, no. 2, pp. 119-131, 2019.

[9] M. Karalar and M. Cavusli, "Three dimensional seismic deformation-shear strain-swelling performance of America-California Oroville EarthFill Dam," Geomechanics and Engineering, vol. 24, no. 5 , pp. $443-456,2021$

[10] W. Fuentes, T. Triantafyllidis, and A. Lizcano, "Hypoplastic model for sands with loading surface," Acta Geotechnica, vol. 7, no. 3, pp. 177-192, 2012.

[11] J. Hleibieh, D. Wegener, and I. Herle, "Numerical simulation of a tunnel surrounded by sand under earthquake using a hypoplastic model," Acta Geotechnica, vol. 9, no. 4, pp. 631-640, 2013.

[12] Y. Jiang and M. Liu, "Similarities between GSH, hypoplasticity and KCR," Acta Geotechnica, vol. 11, no. 3, pp. 519-537, 2016.

[13] Z. Li, P. Kotronis, S. Escoffier, and C. Tamagnini, "A hypoplastic macroelement for single vertical piles in sand subject to three-dimensional loading conditions," Acta Geotechnica, vol. 11, no. 2, pp. 373-390, 2016.

[14] P.-A. Von Wolffersdorff, "A hypoplastic relation for granular materials with a predefined limit state surface," Mechanics of Cohesive-Frictional Materials, vol. 1, no. 3, pp. 251-271, 1996.

[15] G. Gudehus, "A comprehensive constitutive equation for granular materials," Soils and Foundations, vol. 36, no. 1, pp. 1-12, 1996.
[16] E. Bauer, "Calibration of a comprehensive hypoplastic model for granular materials," Soils and Foundations, vol. 36, no. 1, pp. 13-26, 1996.

[17] M. Saberi, C.-D. Annan, and J.-M. Konrad, "On the mechanics and modeling of interfaces between granular soils and structural materials," Archives of Civil and Mechanical Engineering, vol. 18, no. 4, pp. 1562-1579, 2018.

[18] A. Martinez and J. D. Frost, "The influence of surface roughness form on the strength of sand-structure interfaces," Géotechnique Letters, vol. 7, no. 1, pp. 104-111, 2017.

[19] F. S. Tehrani, F. Han, R. Salgado, M. Prezzi, R. D. Tovar, and A. G. Castro, "Effect of surface roughness on the shaft resistance of non-displacement piles embedded in sand," Géotechnique, vol. 66, no. 5, pp. 386-400, 2016.

[20] M. Haruyama, "Effect of surface roughness on the shear characteristics of granular materials," Soils and Foundations, vol. 9, no. 4, pp. 48-67, 1969.

[21] A. S. Alawneh, A. I. H. Malkawi, and H. Al-Deeky, "Tension tests on smooth and rough model piles in dry sand," Canadian Geotechnical Journal, vol. 36, no. 4, pp. 746-753, 1999.

[22] M. Otsubo, C. O'Sullivan, W. W. Sim, and E. Ibraim, "Quantitative assessment of the influence of surface roughness on soil stiffness," Géotechnique, vol. 65, no. 8, pp. 694-700, 2015.

[23] Y. Wang, X. Liu, M. Zhang, and X. Bai, "Effect of roughness on shear characteristics of the interface between silty clay and concrete," Advances in Civil Engineering, vol. 2020, Article ID 8831759, 9 pages, 2020.

[24] R. P. Jensen, P. J. Bosscher, M. E. Plesha, and T. B. Edil, "DEM simulation of granular media-structure interface: effects of surface roughness and particle shape," International Journal for Numerical and Analytical Methods in Geomechanics, vol. 23, no. 6, pp. 531-547, 1999.

[25] M. Arnold and I. Herle, "Hypoplastic description of the frictional behaviour of contacts," in Proceedings of the Presented at the 6th European Conference on Numerical Methods in Geotechnical Engineering, Graz, Austria, September 2006.

[26] H. Stutz and D. Mašín, "Hypoplastic interface models for finegrained soils," International Journal for Numerical and Analytical Methods in Geomechanics, vol. 41, no. 2, pp. 284-303, 2017.

[27] H. Stutz, D. Mašín, and F. Wuttke, "Enhancement of a hypoplastic model for granular soil-structure interface behaviour," Acta Geotechnica, vol. 11, no. 6, pp. 1249-1261, 2016.

[28] H. H. Stutz and A. Martinez, "Hypoplastic simulation of axisymmetric interface shear tests in granular media," in Proceedings of China-Europe Conference on Geotechnical Engineering, W. Wei and Y. H. Sui, Eds., Springer, Vienna, Austria, pp. 69-73, 2018.

[29] M. A. Ghaffari, Y. Zhang, and S. Xiao, "Molecular dynamics modeling and simulation of lubricant between sliding solids," Journal of Micromechanics and Molecular Physics, vol. 02, no. 2, pp. 1750009-1750014, 2017.

[30] L. Bai, N. Srikanth, E. A. Korznikova, J. A. Baimova, S. V. Dmitriev, and K. Zhou, "Wear and friction between smooth or rough diamond-like carbon films and diamond tips,"Wear, vol. 372-373, pp. 12-20, 2017.

[31] H. Matsuoka and T. Nakai, "Stress-deformation and strength characteristics of soil under three different principal stresses," Proceedings of the Japan Society for Comparative Endocrinology, vol. 1974, no. 232, pp. 59-70, 1974.

[32] I. Herle and G. Gudehus, "Determination of parameters of a hypoplastic constitutive model from properties of grain 
assemblies," Mechanics of Cohesive-Frictional Materials, vol. 4, no. 5, pp. 461-486, 1998.

[33] J. E. Dove and J. B. Jarrett, "Behavior of dilative sand interfaces in a geotribology framework," Journal of Geotechnical and Geoenvironmental Engineering, vol. 128, no. 1, pp. 25-37, 2002.

[34] Z. H. Jin, Q. Yang, C. Chen, W. M. Leng, F. Q. Guo, and C. Y. Zhao, "Experimental study on effects of the roughness on mechanical behaviors of concrete-sand interface," Chinese Journal of Rock Mechanics and Engineering, vol. 37, no. 3, pp. 754-764, 2018.

[35] M. D. Bolton, "The strength and dilatancy of sands," Géotechnique, vol. 36, no. 1, pp. 65-78, 1986.

[36] H. Kishida and M. Uesugi, "Tests of the interface between sand and steel in the simple shear apparatus," Géotechnique, vol. 37, no. 1, pp. 45-52, 1987.

[37] I. Shahrour and F. Rezaie, "An elastoplastic constitutive relation for the soil-structure interface under cyclic loading," Computers and Geotechnics, vol. 21, no. 1, pp. 21-39, 1997. 